J. Dairy Sci. 92:657-669

doi:10.3168/jds.2008-1196

(c) American Dairy Science Association, 2009.

\title{
Effects of dietary supplemental fish oil during the peripartum period on blood metabolites and hepatic fatty acid compositions and total triacylglycerol concentrations of multiparous Holstein cows
}

\author{
M. A. Ballou, ${ }^{1,2}$ R. C. Gomes, S. O. Juchem, and E. J. DePeters \\ Department of Animal Science and Nutritional Biology Graduate Group, University of California, Davis 95616
}

\begin{abstract}
The objectives were to evaluate the effects of dietary fish oil on plasma metabolite, hepatic fatty acid composition, and total triacylglycerol concentrations. Multiparous Holstein cows $(\mathrm{n}=42)$ were completely randomized to 1 of 3 treatments at 3 wk prepartum. Treatments were no supplemental lipid or supplemental lipid from either Energy Booster (Milk Specialties Co., Dundee, IL) or fish oil. Treatment diets were fed from $-21 \mathrm{~d}$ relative to expected date of parturition until $10 \mathrm{~d}$ postpartum. Treatments were fed as a bolus before the a.m. feeding. The dose of lipid fed during the prepartum period was $250 \mathrm{~g}$, whereas approximately $0.92 \%$ of the previous day's dry matter intake was supplemented postpartum. Blood was collected 3 times weekly for determination of plasma metabolites. Liver biopsies were performed at 21 and $10 \mathrm{~d}$ before expected date of parturition and 1 and $14 \mathrm{~d}$ after parturition to determine fatty acid compositions and total triacylglycerol concentrations. Dry matter intake, milk yield, and loss of body weight or body condition score were not affected by supplementing the diet with lipid or by the source of lipid. Supplemental lipid tended to increase plasma glucose and decrease nonesterified fatty acids during the postpartum period. Furthermore, plasma $\beta$-hydroxybutyrate was reduced during the postpartum period in the lipid-supplemented treatments. However, source of supplemental lipid had no influence on any blood metabolite. Supplemental fish oil altered the fatty acid composition of liver phospholipids and triacylglycerols, decreasing total saturated fatty acids and increasing total $\mathrm{n}-3$ and long-chain polyunsaturated fatty acids ( $>20$ carbon fatty acids). Despite the altered fatty acid composition, hepatic total triacylglycerol concentrations were unaffected by supplemental fish
\end{abstract}

\footnotetext{
Received March 20, 2008.

Accepted September 28, 2008.

${ }^{1}$ Corresponding author: michael.ballou@ttu.edu

${ }^{2}$ Current address: Department of Animal and Food Sciences, Texas Tech University, Lubbock 79409.
}

oil. Furthermore, the improved metabolic profile following lipid supplementation did not decrease hepatic total triacylglycerol concentrations.

Key words: hepatic lipidosis, metabolic, n-3 fatty acid, peripartum

\section{INTRODUCTION}

The genetic potential of modern dairy cows predisposes them to dysfunctional lipid metabolism, including severe ketosis and hepatic lipidosis (Douglas et al., 2006). In rodents and humans, fatty acids (FA) modulated lipid metabolism; specifically, n-3 FA decreased lipogenesis and increased FA oxidation (Jump, 2002). However, in dairy cattle a consistent association between the FA composition of cell culture medium or intravenous lipid emulsions and hepatic lipid metabolism has not been shown (Mashek et al., 2002, 2005; Mashek and Grummer, 2003).

Nutrition influences the supply of nutrients to tissues and alters the metabolic status of animals. Supplemental lipid is added to increase the energy density of the diet, and it might improve the energy balance of early lactating dairy cows. However, data on the influence of supplemental lipid on the energy balance of early lactating cows were variable, mostly because of variation in DMI and milk production (Grummer and Carroll, 1991). In addition to the energetic effects that lipids may have on metabolic status, they also modulate metabolism by influencing enzyme activities (Jump, 2002). From a teleological standpoint, it is not surprising that lipids interact with genes and proteins to alter lipid metabolism (Jump, 2002).

The contradictory data from cell culture models in dairy cattle (Mashek et al., 2002; Mashek and Grummer, 2003) and the lack of a positive effect of intravenous fish oil (FO) during a 4-d fast on hepatic lipid metabolism (Mashek et al., 2005) suggested that differences may exist between ruminants and other species in the role that dietary FA play on hepatic lipid metabolism. Therefore, the objectives of the current study were to determine the effects of supplemental FO 
during the peripartum period on blood metabolites and the hepatic FA compositions and total triacylglycerol (TG) concentrations of multiparous Holstein cows.

\section{MATERIALS AND METHODS}

\section{Experimental Design, Cows, and Diets}

Forty-two multiparous Holstein cows were moved to individual pens and randomized to 1 of 3 treatment diets at $21 \mathrm{~d}$ before anticipated date of parturition. Cows were enrolled from June 2006 to November 2006. To limit any confounding effects of seasonal environment on treatments, the mean day of the study at enrollment as well as the standard deviation among treatments were found not to be different before initiation of the study. Treatments were no supplemental lipid (control, $\mathrm{n}=12$ ) or supplemental lipid from either Energy Booster (EB; Milk Specialties Co., Dundee, IL; n = 15) or FO (Omega Proteins, Houston, TX; $\mathrm{n}=15$ ). The unbalanced randomization among treatments was because 6 cows did not complete the study, 3 in each of the EB and FO treatments. The cows were removed from the study because they either calved within $14 \mathrm{~d}$ of initiating treatments $(\mathrm{n}=3)$ or had a health problem unrelated to dietary treatments [milk fever $(\mathrm{n}=1)$, lymphoma $(\mathrm{n}=1)$, and complications with displaced abomasum surgery $(\mathrm{n}=1)$ ]. Thus, 36 cows completed the study (12 in each treatment) and were used in the analyses. Energy booster was chosen as a treatment because it is a highly saturated, rumen-inert lipid source. Treatment diets were fed from $21 \mathrm{~d}$ before expected date of parturition until $10 \mathrm{~d}$ after parturition, which is consistent with a close-up and fresh-cow pen-feeding regimen, respectively.

Treatments were fed as a bolus immediately before the a.m. feeding. The bolus was offered within $15 \mathrm{~min}$ of collecting the prior day's refusals. The dose of lipid during the prepartum period was $250 \mathrm{~g} / \mathrm{d}$, whereas the dose in the postpartum period was $1 \%$ of the previous day's as-fed intake (92\% DM). Preliminary studies indicated that supplementing the FO used in the present study at $250 \mathrm{~g} / \mathrm{d}$ during the prepartum period did not have adverse effects on DMI; however, the same dose supplemented during the early postpartum period suppressed DMI. Therefore, the dose of FO during the postpartum period was subsequently based on data from Donovan et al. (2000), where DMI was not affected when $1 \%$ FO was supplemented in the diet. The composition of the bolus was $150 \mathrm{~g}$ each of rolled barley grain, shredded beet pulp, and cane molasses plus $550 \mathrm{~g}$ of the respective TMR plus the supplemental lipid source. Control cows were fed the same bolus without the supplemental lipid. After the entire bolus was consumed, within ap- proximately $10 \mathrm{~min}$, each cow was offered ad libitum either a single prepartum diet before parturition or a lactation diet postpartum. Immediately after parturition cows were switched to the lactation diet and milked twice daily. Milk yield was determined for the a.m. and p.m. milkings on 7 and 14 DIM. Body weight and BCS were determined at study enrollment, parturition, and d 10 and $21 \mathrm{~d}$ after parturition. The BCS (scale of $1=$ thin to $5=$ obese; Wildman et al., 1982) were assigned by the same individual throughout the study. Health records were maintained for all cows. All animal care was approved by the Animal Care and Use Committee of the University of California at Davis.

The amounts of feed offered and refused were measured daily. Samples of the TMR were collected twice weekly, composited by month, and frozen at $-20^{\circ} \mathrm{C}$ until analyzed for DM, CP, NDF, ADF, Ca, P, K, Mg, and $\mathrm{Na}$ by wet chemistry techniques at a commercial laboratory (Cumberland Valley Analytical Services, Maugansville, MD). In addition, sulfur and chloride ions were determined for the prepartum TMR. For energy calculations, the summative energy equation of Weiss et al. (1992) was used to predict total digestible nutrients at maintenance, and the NRC (2001) equations were used to calculate $\mathrm{NE}_{\mathrm{L}}$. Dietary cation-anion difference was calculated using the following equation: $(\mathrm{Na}+\mathrm{K})-(\mathrm{Cl}+\mathrm{S})$.

\section{Sampling of Blood and Plasma Metabolite Analyses}

Peripheral blood was sampled from a coccygeal vein or artery at enrollment and every Monday, Wednesday, and Friday from $21 \mathrm{~d}$ before expected parturition to $21 \mathrm{~d}$ after parturition. Blood collected from $21 \mathrm{~d}$ prepartum to $10 \mathrm{~d}$ postpartum was sampled immediately before the a.m. feeding, whereas blood collected after $10 \mathrm{~d}$ postpartum was collected approximately $2 \mathrm{~h}$ after the a.m. feeding because the cows had returned to the general herd. Blood samples were collected in evacuated tubes (Vacutainer, Becton Dickinson, Rutherford, $\mathrm{NJ}$ ) containing $\mathrm{K}_{2}$ EDTA. Plasma was obtained after centrifugation at $1,200 \times g$ for $15 \mathrm{~min}$ and stored at $-20^{\circ} \mathrm{C}$ until analyzed.

Glucose was analyzed colorimetrically using the ferricyanide method (Hoffman, 1937). Concentration of NEFA was analyzed colorimetrically using a commercial kit (Wako USA, Richmond, VA). Johnson and Peters (1993) described a micro-method using reduced sample and reagent volumes; however, the concentrations of the commercial reagents were recently changed [Wako NEFA-HR(2) reagents]. Therefore, reagent dilutions and volumes used in the Johnson and Peters (1993) paper were no longer valid and were modified. The modified procedure was as follows: 1 vial of color 
reagent A was diluted with $50 \mathrm{~mL}$ of solvent A diluent, and inverted until dissolved. Then, $50 \mathrm{~mL}$ of $50 \mathrm{mM}$ phosphate buffer was added and the solution stored at $4^{\circ} \mathrm{C}$. One vial of color reagent $\mathrm{B}$ was diluted with $25 \mathrm{~mL}$ of solvent B diluent and inverted until dissolved; $25 \mathrm{~mL}$ of $50 \mathrm{~m} M$ phosphate buffer was added and the solution stored at $4^{\circ} \mathrm{C}$. The manufacturer states that solvents $\mathrm{A}$ and $\mathrm{B}$ are good for 10 and $21 \mathrm{~d}$ respectively; however, when mixed with $50 \mathrm{~m} M$ phosphate buffer this may not be true and was not evaluated in the current study; all reagents were used within a few hours of reconstitution. Five microliters of standards and unknown samples were pipetted into a 96 -well plate in duplicate, $225 \mu \mathrm{L}$ of color reagent $\mathrm{A}$ was added immediately, and plates were mixed for $5 \mathrm{~s}$ followed by incubation at room temperature for $30 \mathrm{~min}$. Color reagent $\mathrm{B}$ was added $(75 \mu \mathrm{L})$, samples were mixed for $5 \mathrm{~s}$, and then incubated at room temperature for $30 \mathrm{~min}$. Absorbance was measured at $550 \mathrm{~nm}$. $\beta$-Hydroxybutyrate was measured enzymatically using a commercially available kit (Randox Laboratories, Oceanside, CA); the methods used were outlined by the manufacturer; however, modified reagent volumes were used (Juchem, 2007). Briefly, 5 $\mu \mathrm{L}$ of standards, control serum, and unknown samples were added to a 96 -well plate and $170 \mu \mathrm{L}$ of reagent was added. Both NEFA and BHBA assays were measured using a VersaMax microplate spectrophotometer (Molecular Devices, Sunnyvale, CA).

\section{Sampling and Analyses of Liver Tissue}

Percutaneous liver biopsy was performed under local anesthesia to obtain approximately $2 \mathrm{~g}$ of liver tissue (Drackley et al., 1991) at d 21 and 10 prepartum and at 1 and $14 \mathrm{~d}$ after parturition. Tissue was aseptically transferred into cryovials and immediately frozen in liquid $\mathrm{N}_{2}$ until analyses for contents of glycogen (Lo et al., 1970) and TG (DePeters et al., 2001), plus FA composition (DePeters et al., 2001). Glycogen concentrations were determined from 35 to $50 \mathrm{mg}$ (wet weight). A slice of frozen tissue was added in duplicate to a $16-\times 100-\mathrm{mm}$ tube with $0.5 \mathrm{~mL}$ of ice-cold $30 \% \mathrm{KOH}$ with saturated $\mathrm{Na}_{2} \mathrm{SO}_{4}$. Tubes were placed in boiling water for $20 \mathrm{~min}$ or until the solution was homogeneous, removed, and placed on ice until cool. Then, 0.6 $\mathrm{mL}$ of $95 \% \mathrm{ETOH}$ was added to each tube, vortexed, and the tubes incubated on ice for $30 \mathrm{~min}$. Tubes were centrifuged at $850 \times g$ for $20 \mathrm{~min}$ and the supernatant discarded. The glycogen pellet was dissolved in 6 or 12 $\mathrm{mL}$ of distilled water (depending on biopsy date) and $1 \mathrm{~mL}$ was transferred to a new $16-\times 100-\mathrm{mm}$ tube. In a hood, $1 \mathrm{~mL}$ of $5 \%$ phenol and $5 \mathrm{~mL}$ of $>96 \% \mathrm{H}_{2} \mathrm{SO}_{4}$ were added, allowed to stand for $10 \mathrm{~min}$, vortexed, and incubated at room temperature for $15 \mathrm{~min}$. Contents of each vial were transferred to cuvettes and absorbance read at $490 \mathrm{~nm}$. Working glycogen standards were prepared from glycogen type IX from bovine liver (SigmaAldrich, St. Louis, MO) and stored at $-80^{\circ} \mathrm{C}$.

Stock solutions of internal phospholipids (PL) and TG standards ( 4.5 and $5 \mathrm{mg} / \mathrm{mL}$, respectively) were prepared. The stock PL and TG standard solutions were diluted $1: 10$ in 2:1 chloroform:methanol to create working concentrations. One milliliter of each PL and TG internal standard was added to each tube and dried under nitrogen. Two milliliters of ice-cold PBS plus $6.0 \mathrm{~mL}$ of $2: 1$ chloroform:methanol were added to each tube and placed in an ice bath. Approximately $100 \mathrm{mg}$ (wet weight) of liver tissue was sliced, added to each tube, homogenized, and shaken for $15 \mathrm{~min}$. After centrifugation at $1,700 \times g$ for $5 \mathrm{~min}$, the lower phase (total lipids) was transferred to a clean tube and dried under nitrogen. Both PL and TG were separated by thin-layer chromatography using hexane-diethyl etheracetic acid (90:30:1, vol/vol/vol) as the elution phase. An external standard was used to verify the PL and TG fractions. Methyl esters of FA were prepared by incubation with $2 M$ potassium hydroxide in methanol for $15 \mathrm{~min}$ at room temperature. The ester mixture was separated using a Hewlett Packard 5890 gas chromatograph (Hewlett Packard, Avondale, PA) equipped with a flame-ionization detector and a Supelco 2560 100$\mathrm{m}$ capillary column (Supelco, Bellefonte, PA) with a $0.25-\mathrm{mm}$ inside diameter and a $0.20-\mu \mathrm{m}$ film thickness. Hydrogen was used as the carrier gas with a linear flow rate of $27 \mathrm{~cm} / \mathrm{s}$ and a column head pressure of 227.5 $\mathrm{kPa}$. The ester mixture $(1 \mu \mathrm{L})$ was injected using a 7673 auto injector (Hewlett Packard) and subjected to a split vent flow rate of $100 \mathrm{~mL} / \mathrm{min}$. The injector temperature was set at $210^{\circ} \mathrm{C}$ and the detector temperature set at $220^{\circ} \mathrm{C}$, with the column temperature initially set at $70^{\circ} \mathrm{C}$ for $10 \mathrm{~min}$, followed by a programmed increase to $175^{\circ} \mathrm{C}$ at $20^{\circ} \mathrm{C} / \mathrm{min}$, held for $29 \mathrm{~min}$, and increased to $225^{\circ} \mathrm{C}$ at $5^{\circ} \mathrm{C} / \mathrm{min}$ and held for $12 \mathrm{~min}$.

Unknown peak areas were quantified using Chrom Perfect (Justice Innovations Inc., Palo Alto, CA) and compared with a known quantity of an external standard mixture containing all reported FA. This FA standard mixture comprised individual FA obtained from Nu-Chek Prep (Elysian, MN). Total TG and PL per milligram of tissue (wet weight) were calculated from the internal standard. Fatty acids, in addition to being analyzed individually, were grouped by class before analyses, including: saturated FA, monounsaturated FA, and polyunsaturated FA (PUFA), the latter of which were further divided into 18 and $>20$ carbon PUFA, n-6 PUFA, and n-3 PUFA. Hepatic glycogen and lipid fractions are expressed per milligram of wet weight. 
Table 1. Ingredient and nutrient composition (\% of dietary DM unless otherwise noted) of the basal prepartum and postpartum diets fed to multiparous Holstein cows during late pregnancy and early lactation

\begin{tabular}{|c|c|c|}
\hline \multirow[b]{2}{*}{ Item } & \multicolumn{2}{|c|}{ Diet } \\
\hline & Prepartum & Lactating \\
\hline \multicolumn{3}{|l|}{ Ingredient } \\
\hline Low-DCAD alfalfa hay, chopped & 31.0 & - \\
\hline Lactating alfalfa hay, chopped & - & 49.9 \\
\hline Oat hay, chopped & 20.6 & - \\
\hline Almond hulls & 10.4 & 9.2 \\
\hline Beet pulp, shredded & 3.4 & 4.8 \\
\hline Corn, steam-flaked & 11.4 & 14.8 \\
\hline Barley, steam rolled & 7.0 & 10.1 \\
\hline Soybean meal & 1.2 & 4.9 \\
\hline Dried distillers grains & - & 3.1 \\
\hline Fat & - & 0.8 \\
\hline Salt & - & 0.4 \\
\hline Postpartum vitamin mineral mix ${ }^{1}$ & - & 2 \\
\hline Prepartum vitamin mineral mix $^{2}$ & 5.8 & - \\
\hline Anionic supplement ${ }^{3}$ & 9.2 & - \\
\hline \multicolumn{3}{|l|}{ Nutrient content ${ }^{4}$} \\
\hline DM & $92.1 \pm 0.5$ & $91.9 \pm 0.2$ \\
\hline $\mathrm{CP}$ & $13.9 \pm 0.3$ & $19.4 \pm 0.7$ \\
\hline $\mathrm{ADF}$ & $30.9 \pm 0.3$ & $22.9 \pm 0.5$ \\
\hline $\mathrm{NDF}$ & $43.4 \pm 0.6$ & $29.7 \pm 0.7$ \\
\hline Ether extract & $2.4 \pm 0.06$ & $3.4 \pm 0.10$ \\
\hline NFC & 34.0 & 39.7 \\
\hline $\mathrm{NE}_{\mathrm{L}}, \mathrm{Mcal} / \mathrm{kg}$ of $\mathrm{DM}$ & $1.38 \pm 0.01$ & $1.55 \pm 0.02$ \\
\hline $\mathrm{Ca}$ & $0.78 \pm 0.04$ & $0.89 \pm 0.03$ \\
\hline $\mathrm{P}$ & $0.29 \pm 0.01$ & $0.40 \pm 0.02$ \\
\hline $\mathrm{Mg}$ & $0.47 \pm 0.02$ & $0.43 \pm 0.04$ \\
\hline $\mathrm{K}$ & $1.38 \pm 0.05$ & $2.15 \pm 0.13$ \\
\hline $\mathrm{Na}$ & $0.21 \pm 0.003$ & $0.38 \pm 0.02$ \\
\hline $\mathrm{S}$ & $0.21 \pm 0.003$ & - \\
\hline $\mathrm{Cl}$ & $1.13 \pm 0.02$ & - \\
\hline DCAD, $\mathrm{mEq} / \mathrm{kg}$ & -0.84 & - \\
\hline
\end{tabular}

${ }^{1} \mathrm{Mix}$ contained a minimum of $8.5 \% \mathrm{Ca}, 4.5 \% \mathrm{P}, 6.5 \% \mathrm{Mg}, 1.0 \% \mathrm{~K}$, $1.6 \% \mathrm{~S}, 500 \mathrm{mg}$ of $\mathrm{Cu} / \mathrm{kg}, 2,000 \mathrm{mg}$ of $\mathrm{Mn} / \mathrm{kg}, 17 \mathrm{mg}$ of Se $/ \mathrm{kg}, 3,250$ $\mathrm{mg}$ of $\mathrm{Zn} / \mathrm{kg}, 44 \mathrm{mg}$ of I/ $\mathrm{kg}, 400,000 \mathrm{IU}$ of vitamin A $/ \mathrm{kg}, 140,000 \mathrm{IU}$ of vitamin $\mathrm{D} / \mathrm{kg}$, and $3,150 \mathrm{IU}$ of vitamin $\mathrm{E} / \mathrm{kg}$.

${ }^{2} \mathrm{Mix}$ contained a minimum of $3.0 \% \mathrm{Ca}, 1.0 \% \mathrm{P}, 0.4 \% \mathrm{Mg}, 1.0 \% \mathrm{~K}$, $145 \mathrm{mg}$ of $\mathrm{Cu} / \mathrm{kg}, 615 \mathrm{mg}$ of $\mathrm{Mn} / \mathrm{kg}, 3.7 \mathrm{mg}$ of Se $/ \mathrm{kg}, 4.5 \mathrm{mg}$ of I/kg, $97,000 \mathrm{IU}$ of vitamin $\mathrm{A} / \mathrm{kg}, 22,000 \mathrm{IU}$ of vitamin $\mathrm{D} / \mathrm{kg}$, and $1,650 \mathrm{IU}$ of vitamin $\mathrm{E} / \mathrm{kg}$.

${ }^{3}$ SoyChlor 16-7 (West Central Soy, Ralston, IA)

${ }^{4}$ Nutrient content based on monthly composites of TMR samples $(\mathrm{n}=$ 7 for each TMR). Values for NFC and DCAD were estimated by the NRC (2001) model using mean composition data.

\section{Statistical Analyses}

Continuous data with repeated measurements within experimental units were analyzed by restricted maximum likelihood ANOVA for a completely randomized design using the Mixed procedure of SAS (version 9.1, 2003; SAS Institute, Cary, NC). A linear, mixed model with the fixed effects of treatment, day, and the interaction of treatment by day was fitted. Baseline measurements were used as covariates in the blood metabolite, BW, BCS, and liver composition analyses. All cows were fed a common baseline diet for approximately 40 d before study enrollment. The random effect was cow nested within treatment. The covariance structure for the within-subject measurements was evaluated and chosen for each analysis based on the Schwarz's Bayesian information criterion. Degrees of freedom for F-tests of the fixed effects were estimated using Kenward-Rogers approximation. Contrasts were performed to determine the effects of supplemental lipid and the effect of source of lipid. Repeated data were tested for normality of the residuals by evaluating the Shapiro-Wilk statistic, normal probability plots of the residuals, and histograms of the residuals using the Univariate procedure of SAS (version 9.1, 2003). Means separation were performed at each day for significant treatment $\times$ day interactions using a sliced effect multiple comparison approach with a Tukey-Kramer adjustment (SAS version 9.1, 2003). Separate ANOVA were conducted for blood metabolites during the prepartum and postpartum periods. Least squares means $( \pm \mathrm{SEM})$ are reported throughout. A treatment difference of $P \leq 0.05$ was considered significant and $0.05<P \leq 0.10$ was considered a tendency.

\section{RESULTS}

\section{DMI, Milk Yield, BCS, and BW}

There were no differences among treatments at the start of the experiment for either lactation number $(2.8$ \pm 0.3 ) or the average day of the study at enrollment. Ingredient and chemical compositions of the prepartum and postpartum diets are shown in Table 1, and the

Table 2. Fatty acid profile ${ }^{1}$ of Energy Booster and fish oil

\begin{tabular}{lcc}
\hline & \multicolumn{2}{c}{ Lipid supplement ${ }^{2}$} \\
\cline { 2 - 3 } Fatty acid, $100 \mathrm{~g} / \mathrm{kg}$ of fatty acids & Energy Booster & Fish oil \\
\hline & & \\
C14:0 & 2.19 & 8.32 \\
C16:0 & 29.1 & 16.88 \\
C16:1 & 0.56 & 10.87 \\
C18:0 & 55.26 & 3.17 \\
C18:1 & 3.51 & 5.92 \\
C18:1 all trans & 3.27 & 4.42 \\
C18:2 n-6 & 0.52 & 1.52 \\
Conjugated linoleic acid, cis-9 trans-11 & ND & ND \\
C18:3 n-3 & 0.03 & 2.08 \\
C20:3 n-6 & ND & 0.22 \\
C20:4 n-6 & ND & 0.93 \\
C20:5 n-3 & ND & 13.16 \\
C22:4 n-6 & ND & 0.29 \\
C22:5 n-6 & ND & 0.65 \\
C22:5 n-3 & ND & 2.42 \\
C22:6 n-3 & ND & 12.46 \\
Unknown & 2.37 & 9.74 \\
n-6:n-3 & 17.33 & 0.12 \\
\hline
\end{tabular}

${ }^{1}$ Fatty acid profile of interest.

${ }^{2}$ Energy Booster (Milk Specialties Co., Dundee, IL) and fish oil (Omega Proteins, Houston, TX).

${ }^{3} \mathrm{ND}=$ nondetectable. 
FA compositions of the lipid supplements are shown in Table 2. There was no effect of either supplemental lipid or source of lipid on DMI, milk yield, or changes in BW or BCS (Table 3).

\section{Hepatic PL and TG Fatty Acid Compositions}

Supplementing FO peripartum decreased all n-6 FA in hepatic PL with the exception of docosapentaenoic acid (C22:5 n-6; DPAn-6), which increased in FO (Table 4). As expected, supplemental FO increased eicosapentaenoic acid (EPA), docosapentaenoic acid (C22:5 n-3; DPAn-3), and docosahexaenoic acid (DHA). Supplementing FO increased the proportion of all trans-C18:1 isomers and decreased the cis-C18:1 isomers. Significant interactions of treatment with day were observed (Table 4). Fish oil decreased linoleic acid (C18:2 n-6; LA; Figure 1a) and $\gamma$ linolenic acid (C18:3 n-6; GLA; Figure 1b) at d 10 prepartum and d 1 postpartum, but FO was not different from the control and EB treatments at d 14 postpartum. Furthermore, FO decreased dihomo- $\gamma$ linolenic acid (C20:3 n-6; DGLA; Figure 1c) and arachidonic acid (C20:4 n-6) at d 10 prepartum and 1 and $14 \mathrm{~d}$ postpartum. The increased concentrations of EPA (Figure 2a) and DHA (Figure 2c) were rapid and had reached a plateau at d 10 prepartum in cows supplemented with FO. Concentrations of EPA and DHA were unchanged during the peripartum period in control and EB cows. Docosapentaenoic acid $\mathrm{n}-3$ decreased during the peripartum period (Figure $2 \mathrm{~b}$ ) in control and EB cows, and was increased at d 10 prepartum and $\mathrm{d} 1$ postpartum in cows supplemented with FO.

Supplementing FO was less effective in altering the n-6 FA composition of the hepatic TG fraction (Table
5) compared with the PL fraction (Table 4). Hepatic TG concentration of GLA was reduced and DPAn-6 was increased in FO cows, similar to the response observed for the PL fraction. No other n- 6 FA were altered following FO supplementation. In contrast, the n-3 FA including EPA, DPAn-3, and DHA all increased in FO. Significant interactions of treatment with day were observed (Table 5). $\gamma$-Linolenic acid increased in control and $\mathrm{EB}$ cows over the peripartum period but not in the FO-supplemented cows (Figure 3a). The increase in DPAn-6 following supplemental FO was gradual and remained elevated at d 14 postpartum compared with control and EB cows (Figure 3b). The increase in EPA concentration in hepatic TG was rapid for cows supplemented with FO (Figure 4a), reaching a new plateau by d 10 prepartum. Concentrations of DPAn-3 (Figure 4b) and DHA (Figure 4c) both increased with time, although not as rapidly as EPA.

In the hepatic PL pool, supplementing FO dramatically increased the proportion of C18:1-all trans isomers (Figure 5a) at d -10, but after parturition, although still significantly greater than control and EB, the differences were not as great. In the TG pool, C18:1-all trans isomers were not different at $\mathrm{d}-10$, but the concentration of these isomers was dramatically increased at $\mathrm{d} 1$ and then returned to near baseline by d 14 postpartum (Figure 5b).

\section{Metabolites in Plasma and Composition of Hepatocytes}

The effects of supplemental lipid and source on peripartum blood metabolites are shown in Table 6 . Prepartum glucose concentrations were not different among treatments. Postpartum glucose concentrations

Table 3. Least squares means for DMI, BCS, and BW during the pre- and postpartum periods

\begin{tabular}{|c|c|c|c|c|c|c|c|c|c|}
\hline \multirow[b]{2}{*}{ Variable } & \multicolumn{3}{|c|}{ Treatment $^{1}$} & \multirow[b]{2}{*}{ SEM } & \multicolumn{3}{|c|}{ Main effects $^{2}$} & \multicolumn{2}{|c|}{ Contrast $^{3}$} \\
\hline & Control & EB & FO & & Trt & Day & Trt $\times$ Day & Lipid & Source \\
\hline \multicolumn{10}{|l|}{$\mathrm{DMI},{ }^{4} \mathrm{~kg} / \mathrm{d}$} \\
\hline Postpartum $^{6}$ & 19.2 & 18.9 & 18.2 & 1.0 & 0.73 & 0.001 & 0.68 & 0.64 & 0.82 \\
\hline Milk yield, ${ }^{7} \mathrm{~kg} / \mathrm{d}$ & 40.2 & 39.9 & 39.6 & 2.0 & 0.98 & 0.001 & 0.29 & 0.86 & 0.91 \\
\hline $\mathrm{BCS}^{8}$ & 3.12 & 3.05 & 3.04 & 0.08 & 0.73 & 0.001 & 0.69 & 0.44 & 0.94 \\
\hline
\end{tabular}

${ }^{1}$ Control diet containing no supplemental lipid during the peripartum period (control) or supplemental lipid, $250 \mathrm{~g}$ (prepartum) or $1 \%$ of the previous day's intake (postpartum) as Energy Booster (EB) or fish oil (FO).

${ }^{2}$ Effects of treatment (Trt) and Trt by day interaction.

${ }^{3}$ Lipid $=$ control vs. EB and FO; source $=\mathrm{EB}$ vs. FO.

${ }^{4} \mathrm{DMI}$ includes the bolus.

${ }^{5}$ Data from 21 to $1 \mathrm{~d}$ before expected date of parturition.

${ }^{6}$ Data from 1 to $10 \mathrm{~d}$ after parturition.

${ }^{7}$ Data from 7 and $14 \mathrm{~d}$ after parturition.

${ }^{8} 1=$ thin to $5=$ obese; Wildman et al. (1982). 

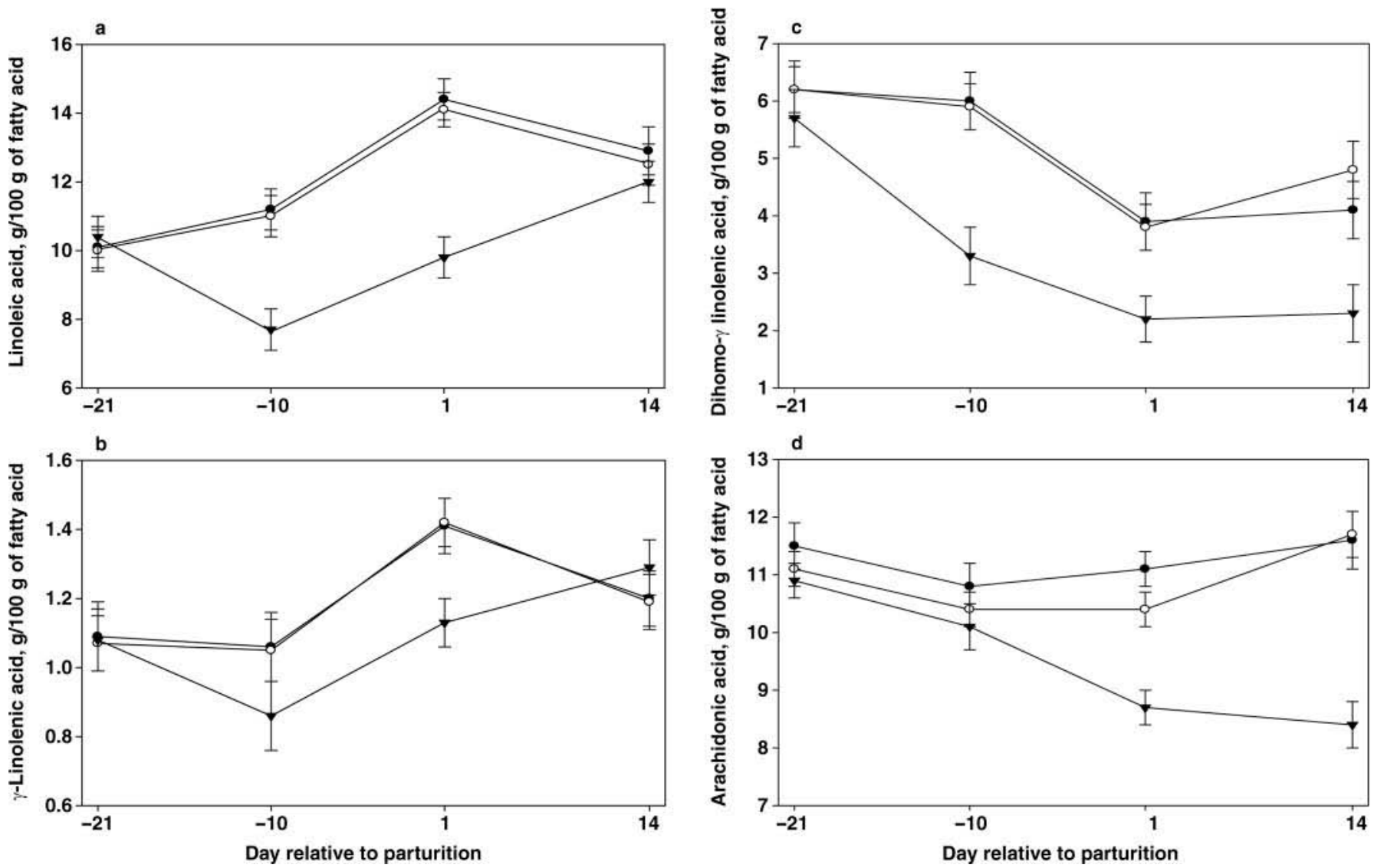

Figure 1. Treatment by day interaction for the proportion ( $\mathrm{g} / 100 \mathrm{~g}$ of fatty acids) of a) linoleic acid, b) $\gamma$-linolenic acid, c) dihomo $\gamma$-linolenic acid, and d) arachidonic acid in hepatic phospholipids. $\bullet=$ control (no supplemental lipids); $\bigcirc=$ EB (supplemented with Energy Booster); and $\boldsymbol{\nabla}=$ FO (supplemented with fish oil). Error bars represent \pm SEM.

Table 4. Least squares means by dietary treatment for weight percentages of fatty acids in hepatic phospholipids during the peripartum period

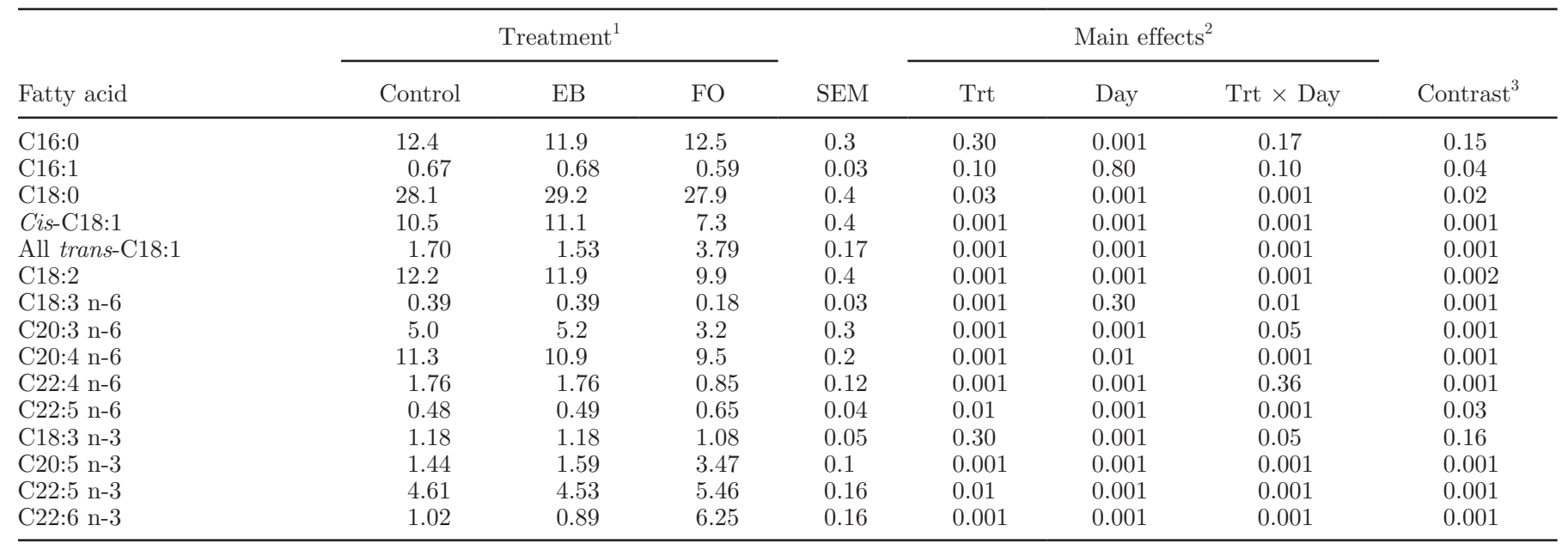

${ }^{1}$ Control diet containing no supplemental lipid during the peripartum period (control) or supplemental lipid, $250 \mathrm{~g}$ (prepartum) or $1 \%$ of the previous day's intake (postpartum) as Energy Booster (EB) or fish oil (FO).

${ }^{2}$ Effects of treatment (Trt) and Trt by day interaction.

${ }^{3} \mathrm{~EB}$ vs. FO. 
tended $(P=0.08)$ to increase in response to lipid feeding, whereas plasma NEFA concentrations during the peripartum period tended $(P=0.06)$ to be reduced with EB and FO compared with control. Prepartum BHBA concentrations were not different; however, similar to plasma NEFA concentrations, plasma BHBA
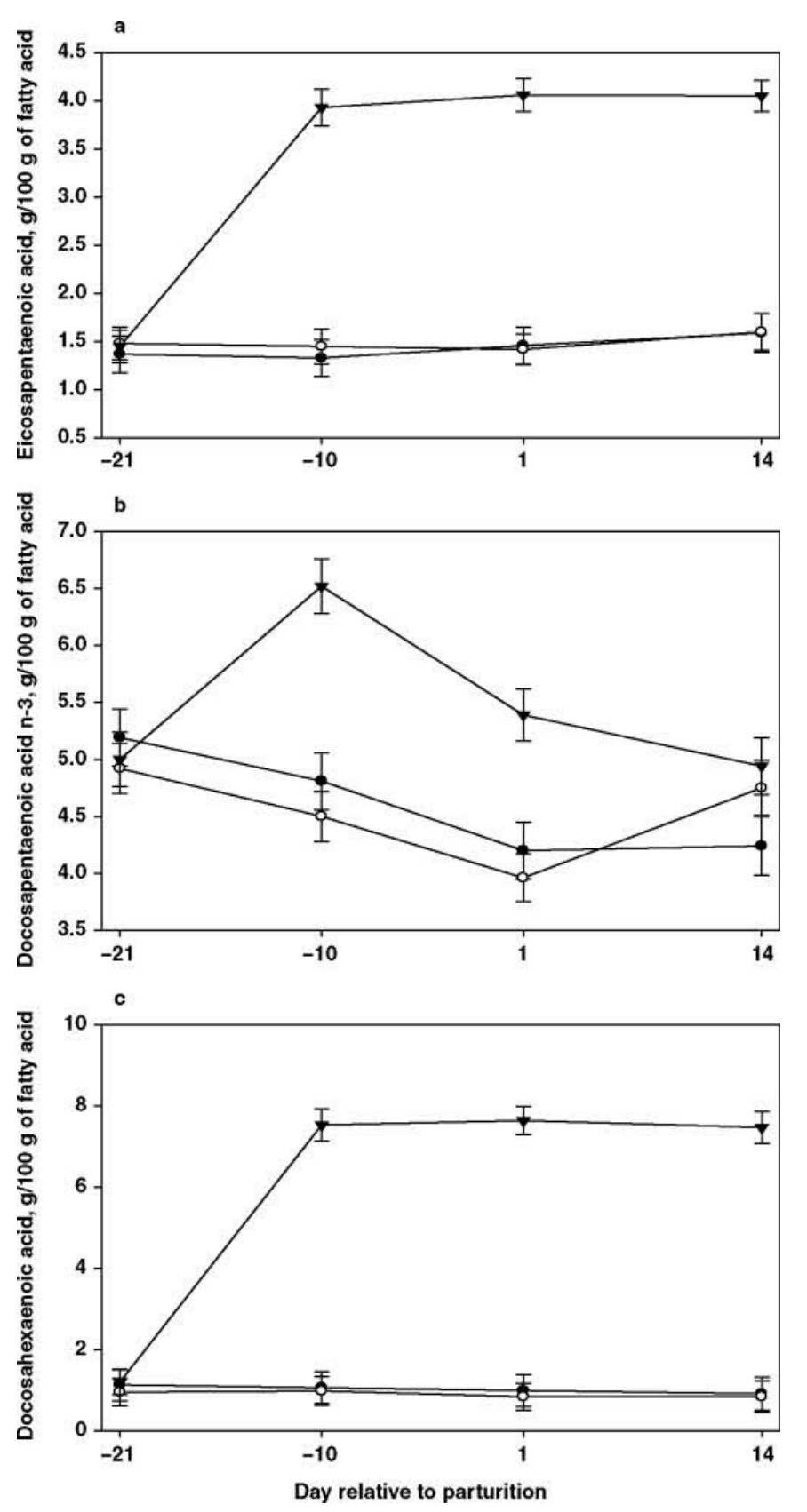

Figure 2. Treatment by day interaction for the proportion (g/100 $\mathrm{g}$ of fatty acids) of a) eicosapentaenoic acid, b) docosapentaenoic acid $\mathrm{n}-3$, and c) docosahexaenoic acid in hepatic phospholipids. - control (no supplemental lipids); $\bigcirc=E B$ (supplemented with Energy Booster); and $\mathbf{\nabla}=$ FO (supplemented with fish oil). Error bars represent \pm SEM were elevated in the control cows during the postpartum period relative to lipid-supplemented cows. Source of lipid supplementation did not influence the blood metabolites measured.

Despite a tendency for a reduction in plasma NEFA in both the prepartum and postpartum periods in lipidsupplemented treatments, analysis of total hepatic TG revealed no differences among treatments (Table 6). Total TG increased with days relative to parturition. Concentrations of hepatic glycogen did not differ for treatment during the peripartum period (Table 6). Hepatic glycogen concentration dramatically decreased by d 1 postpartum and remained low at d 14 postpartum.

\section{DISCUSSION}

Dry matter intake, milk yield, and the changes in BW and BCS were not affected by either supplemental lipid or the source of lipid (Table 3). These findings differ from previous observations in which supplementing FO at 1.8 to $2.0 \%$ of the diet DM suppressed DMI (Donovan et al., 2000; AbuGhazaleh et al., 2002; Whitlock et al., 2002; Mattos et al., 2004). Donovan et al. (2000) reported that DMI was not affected when $1 \% \mathrm{FO}$ was supplemented in the diet, and DMI only decreased when supplementing either 2 or $3 \%$ FO. In the present study, the concentration of supplemental FO during the postpartum period was similar to concentrations reported to have no adverse effects on DMI (Donovan et al., 2000). However, the calculated supply of FO during the prepartum period as a percentage of the DMI was $1.7 \%$, which approached concentrations that previously reduced DMI. In many studies reporting adverse effects of FO on DMI, corn silage was a major component of the forage portion (Donovan et al., 2000; AbuGhazaleh et al., 2002; Whitlock et al., 2002; Mattos et al., 2004). In the present study, the prepartum diet was hay-based rather than silage-based, which may explain the lack of influence of supplemental FO on DMI. In addition, most studies showing adverse effects of FO on DMI have been in lactating dairy cattle; therefore, they are consuming more DMI and subsequently more grams of FO than the prepartum cows in the present study. Thus, a grams per day effect cannot be ruled out.

Supplementing FO decreased all n-6 FA in hepatic PL except DPAn-6 (Table 4). The decreased proportions of $n-6$ FA could be due to allosteric inhibition or transcriptional regulation (Matsuzaka et al., 2002) of elongases and $\Delta^{5}$ - and $\Delta^{6}$-desaturases or to competition between n- 6 and n-3 substrates for incorporation. The increased DPAn-6 in FO cows likely reflected an increased supply of preformed DPAn- 6 with FO (Table 2 ). In addition, desaturation and elongation of LA to DPAn-6 was minimal as reflected by its low baseline 
Table 5. Least squares means by dietary treatment for weight percentages of fatty acids in hepatic triacylglycerols during the peripartum period

\begin{tabular}{|c|c|c|c|c|c|c|c|c|}
\hline Fatty acid & \multicolumn{3}{|c|}{ Treatment $^{1}$} & SEM & \multicolumn{3}{|c|}{ Main effects ${ }^{2}$} & Contrast $^{3}$ \\
\hline C16:0 & 35.9 & 37.1 & 34.9 & 0.6 & 0.05 & 0.001 & 0.05 & 0.05 \\
\hline C18:0 & 12.0 & 12.3 & 11.1 & 0.8 & 0.54 & 0.001 & 0.98 & 0.29 \\
\hline Cis-C18:1 & 19.9 & 18.6 & 17.8 & 0.9 & 0.27 & 0.001 & 0.20 & 0.50 \\
\hline All trans-C18:1 & 2.03 & 2.38 & 3.51 & 0.45 & 0.07 & 0.41 & 0.36 & 0.07 \\
\hline C20:3 n-6 & 0.75 & 0.69 & 0.58 & 0.07 & 0.22 & 0.001 & 0.78 & 0.23 \\
\hline C20:4 n-6 & 1.32 & 1.44 & 1.65 & 0.22 & 0.54 & 0.001 & 0.17 & 0.46 \\
\hline C22:4 n-6 & 0.33 & 0.37 & 0.33 & 0.08 & 0.89 & 0.07 & 0.48 & 0.68 \\
\hline $\mathrm{C} 22: 5$ n-6 & 0.07 & 0.12 & 0.25 & 0.03 & 0.001 & 0.23 & 0.03 & 0.001 \\
\hline C18:3 n-3 & 1.08 & 0.99 & 1.31 & 0.08 & 0.03 & 0.001 & 0.22 & 0.01 \\
\hline C20:5 n-3 & 0.10 & 0.11 & 0.27 & 0.02 & 0.001 & 0.01 & 0.001 & 0.001 \\
\hline C22:5 n-3 & 0.71 & 0.70 & 1.18 & 0.07 & 0.001 & 0.03 & 0.001 & 0.001 \\
\hline
\end{tabular}

${ }^{1}$ Control diet containing no supplemental lipid during the peripartum period (control) or supplemental lipid, $250 \mathrm{~g}$ (prepartum) or $1 \%$ of the previous day's intake (postpartum) as Energy Booster (EB) or fish oil (FO).

${ }^{2}$ Effects of treatment (Trt) and Trt by day interaction.

${ }^{3} \mathrm{~EB}$ vs. FO.

proportion in hepatic PL. The decreased LA (Figure 1a) and GLA (Figure 1b) in FO cows was not evident on d 14 postpartum, only $4 \mathrm{~d}$ after FO supplementation had ended, whereas decreased DGLA (Figure 1c) and arachidonic acid (Figure 1d) in FO cows remained significant at $\mathrm{d} 14$. The discrepancy between the effects of FO on the proportions of the various n- 6 FA at $d 14$ postpartum is unknown.

Supplemental FO was less effective in altering the proportions of the n- 6 FA in the TG pool (Table 5). $\gamma$-Linolenic acid decreased in FO cows (Figure 3a), which was consistent with inhibition of the rate-limiting enzyme, $\Delta^{6}$-desaturase (Uauy et al., 2000). Similar to the PL pool, supplementing FO increased the proportion of TG DPAn-6 (Figure 3b).

Eicosapentaenoic acid, DPAn-3, and DHA all increased in the TG pool following supplemental FO (Figure 4); however, the increase was modest relative to the increase observed for the PL pool (Figure 2). Polyunsaturated FA, particularly $>20$ carbon PUFA, were preferentially incorporated into the sn- 2 position of PL (Monroy et al., 1972); therefore, the potential to alter the $>20$ carbon PUFA composition of the PL fraction is greater. In hepatocytes, the absolute increase in DHA was greater than for EPA, which contrasted with both plasma and peripheral blood mononuclear cell pools in calves supplemented with a similar FO (M. A. Ballou and E. J. DePeters; unpublished data). The increase was rapid for both EPA and DHA in PL, which reached a new steady state for both FA by $10 \mathrm{~d}$ prepartum. In the TG pool, EPA also reached a new

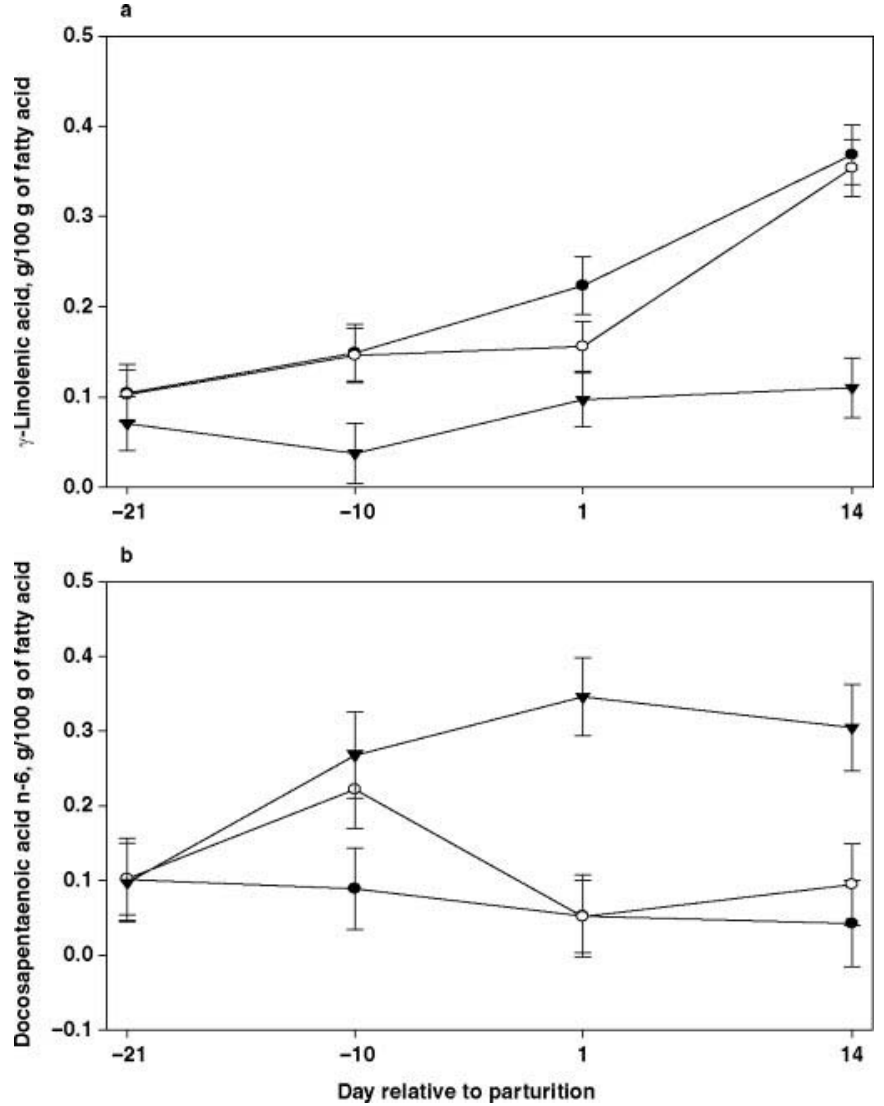

Figure 3. Treatment by day interaction for the proportion (g/100 $\mathrm{g}$ of fatty acids) of a) $\gamma$-linolenic acid and b) docosapentaenoic acid n- 6 in hepatic triacylglycerols. $\bullet=$ control (no supplemental lipids); $\bigcirc=$ EB (supplemented with Energy Booster); and $\boldsymbol{\nabla}=$ FO (supplemented with fish oil). Error bars represent \pm SEM. 
steady state by $10 \mathrm{~d}$ prepartum, whereas the increases in DPAn-3 and DHA were more gradual. The absolute increase in the proportion of EPA in the TG pool was the least for the n-3 $>20$ carbon PUFA. The absolute increase in DPAn-3 was greater than EPA, which was interesting because of the low concentration of DPAn-3 relative to EPA in the FO supplement. These data suggest a preference for $>22$ carbon FA in the TG pool of hepatocytes and likely a further elongation of EPA to DPAn-3.

Supplementing FO dramatically increased C18:1-all trans FA in the PL pool at d 10 prepartum (Figure 5a), which is consistent with increased biohydrogenation of PUFA. However, at d 1 and 14 after parturition their concentration was dramatically reduced, although still significantly greater than either control or EB. The C18:1-all trans FA also increased in the TG fraction with FO supplementation but not until d 1 after parturition, later than the response observed for PL (Figure 5b). The increased C18:1-all trans FA in the PL fraction on d 10 prepartum without an increase in the TG fraction was contrary to previous observations (Schrock and Conner, 1975), where C18:1-all trans FA increased to a greater extent in the TG fraction of serum than the PL pool. An explanation for the redistribution of C18:1-all trans $\mathrm{FA}$ from the PL pool during the prepartum period to the TG pool at parturition is not readily apparent, especially given that the total pool size of hepatic PL was not altered during the peripartum period (data not shown). Furthermore, on d 14 postpartum it was unclear whether the TG C18:1-all trans was re-distributed to another pool (i.e.; milk fat) or the kinetics to reach a new steady state was rapid and C18:1-all trans had reduced to baseline proportions within $4 \mathrm{~d}$ of removing $\mathrm{FO}$ from the diet.

There was no effect of supplemental lipid or source of lipid on blood glucose concentrations during the prepartum period (Table 6); however, over the postpartum period, glucose concentrations tended to be lower in the control cows relative to cows supplemented with lipid. Supplemental lipid had a glucose-sparing effect (Yang et al., 1978); however, increased blood glucose concentrations are not consistently observed during lipid supplementation (Grummer and Carroll, 1991). A recent review suggested that blood glucose often decreases with supplemental lipid (van Knegsel et al., 2005), which the authors attributed to an imbalance between glucogenic and lipogenic substrates for oxidation in lactating cows. Milk energy output was not recorded in the present study; therefore, improved energy status of cows supplemented with lipid in the present study cannot be excluded.

During both the pre- and postpartum periods, cows supplemented with lipid tended to experience reduced plasma NEFA concentrations (Table 6), which differed from previous reports indicating either no effect (Douglas et al., 2004; 2006) or increased (Grummer and Carroll, 1991) NEFA concentrations when lipid was supplemented in the diet. It was suggested that increased concentration of NEFA after lipid supplementation resulted from incomplete removal of hydrolyzed
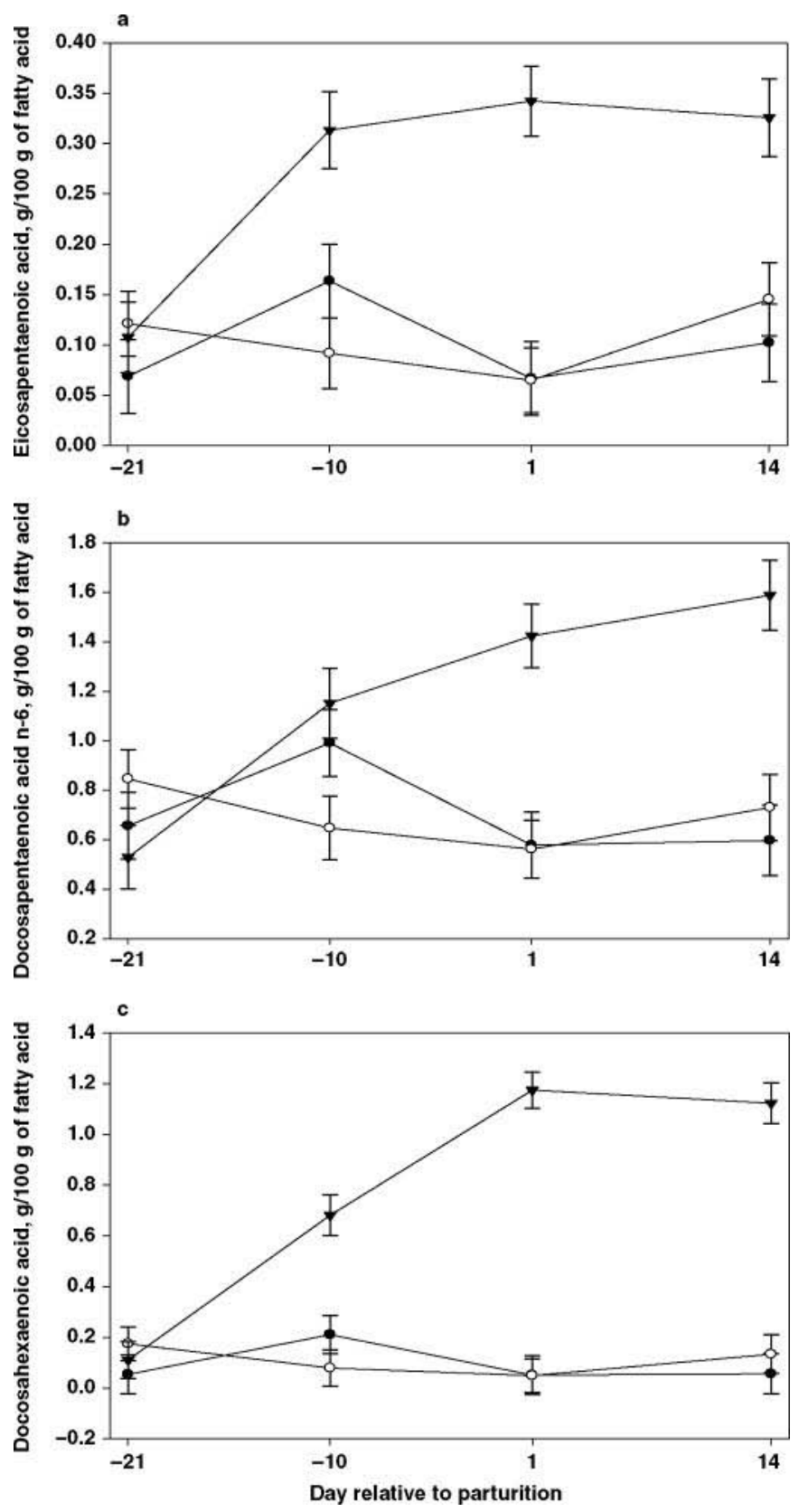

Figure 4. Treatment by day interaction for the proportion (g/100 $\mathrm{g}$ of fatty acids) of a) eicosapentaenoic acid, b) docosapentaenoic acid $\mathrm{n}-3$, and c) docosahexaenoic acid in hepatic triacylglycerols. $\bullet=$ control (no supplemental lipids); $\bigcirc=$ EB (supplemented with Energy Booster); and $\boldsymbol{\nabla}=$ FO (supplemented with fish oil). Error bars represent \pm SEM. 
FA at the tissue because, despite the well-known fact that the mammary gland incorporates NEFA into milk fat, the arterio-venous difference of NEFA across the mammary gland is negligible (Grummer and Carroll, 1991). Furthermore, dietary fatty acids were found in the plasma NEFA pool during the postprandial period in humans (Frayn et al., 1994). Recently, van Knegsel et al. (2007) reported that feeding a lipogenic diet containing high NDF + lipid compared with an isoenergetic glucogenic diet that contained high NFC and low NDF + lipid during the peripartum period and until peak lactation resulted in cows tending to have increased plasma concentration of NEFA that was associated with a tendency for reduced plasma insulin concentrations over the first $9 \mathrm{wk}$ of lactation. Based on results showing increased milk energy and reduced energy retention as fat in the cows fed the lipogenic diet, those researchers concluded that feeding a lipogenic diet during early lactation partitioned nutrients toward milk and away from body tissue compared with feeding a glucogenic diet, which accounted for the increased plasma NEFA in the cows fed the lipogenic diet. An important difference between the current study and those conducted by van Knegsel et al. (2007) was that the glucogenic or NFC concentrations of the diets in the present study were similar between the control and lipid-supplemented diets. The exact mechanism for the modest reduction in plasma NEFA in lipid-supplemented cows in the current study is unknown, and improved energy status cannot be ruled out. Taken together with the recent reports by van Knegsel et al. (2005, 2007), these data reiterate the complex relationship between
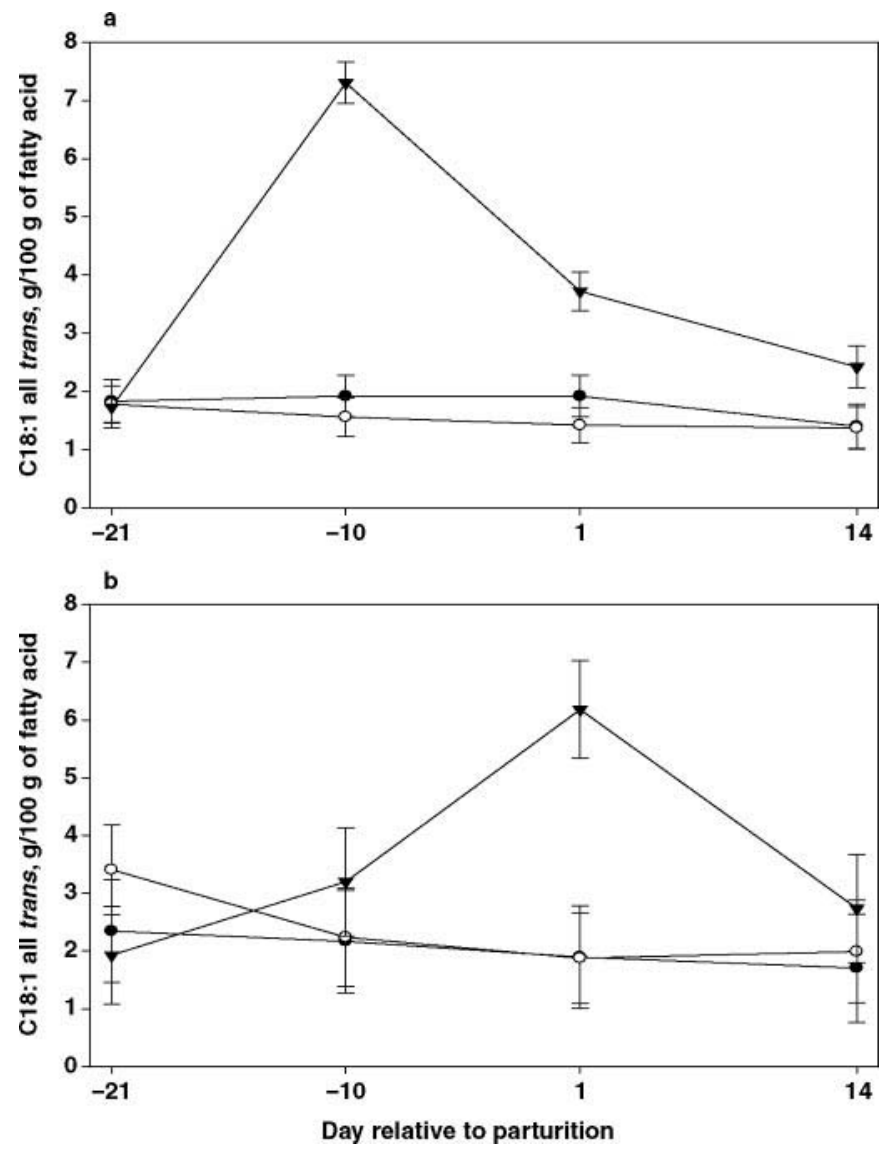

Figure 5. Treatment by day interaction for the proportion $(\mathrm{g} / 100$ $\mathrm{g}$ of fatty acids, FA) of C18:1-all trans FA in a) phospholipid and b) triacylglycerol pools. $\bullet=$ control (no supplemental lipids); $\mathrm{O}=\mathrm{EB}$ (supplemented with Energy Booster); and $\boldsymbol{\nabla}=$ FO (supplemented with fish oil). Error bars represent \pm SEM.

Table 6. Least squares means for plasma metabolites during the pre- and postpartum periods

\begin{tabular}{|c|c|c|c|c|c|c|c|c|c|}
\hline \multirow[b]{2}{*}{ Variable } & \multicolumn{3}{|c|}{ Treatment $^{1}$} & \multirow[b]{2}{*}{ SEM } & \multicolumn{3}{|c|}{ Main effects ${ }^{2}$} & \multicolumn{2}{|c|}{ Contrast $^{3}$} \\
\hline & Control & EB & FO & & Trt & Day & Trt $\times$ Day & Lipid & Source \\
\hline \multicolumn{10}{|l|}{ Glucose, mg/dL } \\
\hline Postpartum $^{5}$ & 47.2 & 49.7 & 50.1 & 1.2 & 0.20 & 0.002 & 0.88 & 0.08 & 0.80 \\
\hline \multicolumn{10}{|l|}{$\mathrm{NEFA}, \mu \mathrm{Eq} / \mathrm{L}$} \\
\hline Prepartum & 357 & 254 & 294 & 37 & 0.10 & 0.001 & 0.89 & 0.06 & 0.34 \\
\hline Prepartum & 623 & 527 & 562 & 88 & 0.95 & - & - & 0.87 & 0.77 \\
\hline Postpartum & 1,562 & 1,072 & 1,051 & 140 & 0.02 & 0.001 & 0.28 & 0.01 & 0.92 \\
\hline Hepatic glycogen, $\%$ wet weight & 2.43 & 2.33 & 2.21 & 0.26 & 0.82 & 0.001 & 0.40 & 0.61 & 0.73 \\
\hline Hepatic triacylglycerols, $\%$ wet weight ${ }^{6}$ & 4.51 & 4.16 & 3.94 & 0.82 & 0.59 & 0.001 & 0.79 & 0.87 & 0.31 \\
\hline
\end{tabular}

${ }^{1}$ Control diet containing no supplemental lipid during the peripartum period (control) or supplemental lipid, $250 \mathrm{~g}$ (prepartum) or $1 \%$ of the previous day's intake (postpartum) as Energy Booster (EB) or fish oil (FO).

${ }^{2}$ Effects of treatment (Trt) and Trt by day interaction.

${ }^{3}$ Lipid $=$ control vs. $\mathrm{EB}$ and $\mathrm{FO}$; source $=\mathrm{EB}$ vs. FO.

${ }^{4}$ Data from -21 to $-1 \mathrm{~d}$ relative to expected date of parturition.

${ }^{5}$ Data from 1 to $21 \mathrm{~d}$ after parturition.

${ }^{6}$ Total triacylglycerols. 
lipid and glucose metabolism in early lactating cows (Drackley et al., 1991).

There was no treatment effect on prepartum plasma BHBA concentrations (Table 6) despite differences in plasma NEFA during the prepartum period. However, over the postpartum period, when plasma BHBA concentrations were dramatically increased, lipid supplementation decreased BHBA concentrations. No effect due to source of supplemental lipid was evident. In their review, Grummer and Carroll (1991) reported that lipid supplementation either had no effect or decreased plasma BHBA when the control diet resulted in markedly elevated BHBA. As indicated previously, an improved energy status of cows supplemented with lipid in the present study cannot be excluded as a basis for decreasing plasma NEFA and BHBA concentrations. However, at the level and method of supplemental lipid inclusion in the present study, supplemental lipid, either $\mathrm{FO}$ or $\mathrm{EB}$, improved metabolic variables irrespective of energy status.

The lack of an effect of source of lipid in the present study indicated that the metabolic effects of supplementing FO to peripartum cows was due only to the additional lipid and not any alteration in metabolism because of changes in the degree of unsaturation of FA of the dietary lipid source. Data on the effects of FO on glucose and lipid metabolism in early lactating dairy cows are limited (Mattos et al., 2004; Moussavi et al., 2007). Moussavi et al. (2007) supplemented cows with either fish meal or calcium salts of FO FA during early lactation, and their findings differed from those of the present study. Cows fed either the greatest concentration of fish meal ( $5 \%$ of DM) or the calcium salts of $\mathrm{FO}$ FA had increased concentrations of glucose and insulin compared with other isoenergetic treatments with similar lipid content (Moussavi et al., 2007). The response was dependent on the dose of EPA + DHA, and only the greatest quantity of EPA + DHA (approximately $25 \mathrm{~g} / \mathrm{d}$ ) had positive effects on blood glucose; in the current study cows received $64 \mathrm{~g} / \mathrm{d}$ prepartum and approximately $45 \mathrm{~g} / \mathrm{d}$ postpartum. The lack of an effect in the present study may be related to the higher dose of EPA + DHA.

Similar to the present study, neither plasma NEFA nor BHBA was affected by increasing the dose of fish meal or the feeding of calcium salts of FO FA (Moussavi et al., 2007). Adipose tissue from early lactating cows showed signs of insulin resistance (Bell and Bauman, 1997). Further, saturated lipid sources increased the resistance (Chilliard, 1993). Unfortunately, there are no data evaluating the effects of supplemental FO on insulin sensitivity in dairy cattle; regardless, supplemental FO did not improve plasma NEFA or BHBA concentrations when compared with a saturated lipid source.

Despite the tendency for lipid supplementation to decrease plasma NEFA and increase plasma glucose, there was no effect of lipid supplementation on either hepatic total TG or glycogen (Table 6) concentrations during the peripartum period. The interaction between plasma NEFA and total hepatocyte TG concentrations is complex, as is evident in the study of Douglas et al. (2006), where cows undergoing feed restriction during the dry period had reduced total hepatic lipid and TG at $\mathrm{d} 1$ after parturition despite similar plasma NEFA concentrations. These data suggest an increased oxidative capacity of hepatocytes from feed-restricted cows. Furthermore, an explanation for the lack of an effect on liver TG accumulation in the present study was that the increased NEFA in the control cows was associated with increased plasma BHBA concentrations, which suggested partitioning NEFA toward ketone body production rather than esterification. In agreement, Douglas et al. (2004) reported that supplemental lipid during the prepartum period did not influence the concentrations of hepatic TG after parturition.

Despite significantly altering the FA composition of hepatic lipids, the present study indicated that supplementing FO to peripartum cows did not influence hepatic TG metabolism. This observation differed from previous findings with rodents where increasing the intake of PUFA, either n-6 or n-3 FA, suppressed hepatic de novo lipogenesis within 1 d (Jump et al., 1993). Jump and Clarke (1999) and Mater et al. (1999) later reported that n-6 and n-3 PUFA suppressed the transcription of hepatic genes involved in lipogenesis, including FA synthase, the spot 14 protein, and stearoyl CoA desaturase through suppression of the transcription factor sterol regulatory element binding protein-1c (SREBP-1c). Furthermore, n-3 FA also induced genes involved in FA oxidation (Flatmark et al., 1988; Ren et al., 1997). The EPA + DHA activation of acyl CoA oxidase, the rate-limiting enzyme in peroxisomal oxidation of FA, was dependent on activation of the transcription factor peroxisome proliferator-activated receptor- $\alpha$ (PPAR $\alpha)$, whereas a PPAR $\alpha$-independent mechanism regulated SREBP-1c activity and subsequent lipogenesis (Ren et al., 1997). Recently, Martin et al. (2007) evaluated the role of PPAR $\alpha$ as a hepatic regulator of lipid metabolism in response to a low-fat diet, $4.8 \%$ of the diet. In that study they tested various lipid supplements, including $15 \%$ of the lipid from a $72 \%$ DHA FO. Supplementing either PPAR $\alpha$ knockout or wild type mice with sunflower, linseed, or FO significantly decreased the concentrations of TG in hepatocytes compared with mice supplemented a highly saturated 
lipid. These data were important because they were the first to demonstrate that dietary FA, even at low concentrations similar to that of dairy cattle, influenced gene expression in hepatocytes.

The lack of an effect of FO on total hepatic TG concentrations in the present study could be due to the dose of EPA + DHA, which might be below a threshold needed to alter SREBP-1c and PPAR $\alpha$ transcriptions, or the positive effects of EPA + DHA on lipid oxidation were counterbalanced by the inhibitory effects of C18:1-all trans FA, which previously decreased carnitine palmitoyltransferase-1 and 3-hydroxy-acyl-CoA dehydrogenase activities, and subsequently increased liver TG in rats when compared with rats fed a high saturated lipid diet (Giudetti et al., 2003). However, previous research (Mashek and Grummer, 2003; Mashek et al. 2005) indicated a possible species differences in the regulation of hepatic lipid metabolism by PUFA. In 48-h primary hepatocyte monolayer cultures, incubation with $1 \mathrm{mM}$ EPA, DHA, or EPA + DHA did not demonstrate an ameliorative effect on lipid metabolism compared with $1 \mathrm{~m} M$ stearic acid; in fact, the incubation with DHA increased the metabolism of $\left[1-{ }^{14} \mathrm{C}\right]$ palmitic acid to cellular TG. Furthermore, cell culture medium supplemented with either DHA or EPA + DHA increased the accumulation of total cellular TG (Mashek and Grummer, 2003). In vivo, despite dramatically increased proportions of EPA and DHA in hepatocyte TG (4.69 and $5.01 \mathrm{~g} / 100 \mathrm{~g}$ of $\mathrm{FA}$, respectively) following an intravenous emulsion of FO, total hepatic TG during a 4-d fast were not different when the cows were infused with tallow (Mashek et al., 2005). In the series of studies by Mashek and associates, the incorporations of EPA and DHA into the lipid pools were more dramatic than in the present study; furthermore, the adverse effects of C18:1-all trans FA on lipid metabolism could not negate any positive effects of FO because EPA and DHA were added as purified ethyl ethers or FO infused intravenously. Taken together with the present study, these data provide strong evidence that ruminants may have lost the sensitivity of PUFA-regulated effects on hepatic lipid metabolism. Supplementing unprotected FO during the peripartum period, at a level not to influence DMI, does not ameliorate hepatic lipidosis.

\section{CONCLUSIONS}

Supplemental FO did not adversely affect DMI under the current feeding conditions. Irrespective of energy status, moderate lipid supplementation during the peripartum period to a nonisoenergetic control diet improved the blood metabolic profile of early lactating cows, as evidenced by increased blood glucose and decreased concentrations of NEFA and BHBA, whereas there were no additional benefits of supplementing FO relative to a saturated lipid source. Supplemental FO was effective in altering the FA composition of hepatocytes, increasing both total and n-3 long-chain PUFA ( $>20$ carbon FA) while concomitantly decreasing total saturated FA. However, neither supplemental lipid nor source of lipid supplement decreased peripartum lipid accumulation in hepatocytes. A loss in the sensitivity of PUFA regulation on hepatic lipid metabolism in ruminants, from a teleological perspective, would not be surprising, given the low quantity of absorbed PUFA.

\section{ACKNOWLEDGMENTS}

The authors thank M. K. Yelle and D. Kim for their help with the animals, and S. J. Taylor and J. M. Heguy (University of California, Davis) for laboratory support. The cost of fatty acid analyses was supported by the Dairy Milk Components Laboratory at University of California, Davis. Finally, we acknowledge the product contributions of Omega Proteins Inc. (Houston, TX), Milk Specialties Co. (Dundee, IL), and Pfizer Animal Health (St. Louis, MO).

\section{REFERENCES}

AbuGhazaleh, A. A., D. J. Schingoethe, A. R. Hippen, K. F. Kalscheur, and L. A. Whitlock. 2002. Fatty acid profiles of milk and rumen digesta from cows fed fish oil, extruded soybeans or their blend. J. Dairy Sci. 85:2266-2276.

Bell, A. W., and D. E. Bauman. 1997. Adaptations of glucose metabolism during pregnancy and lactation. J. Mammary Gland Biol. Neoplasia 2:265-278.

Chilliard, Y. 1993. Dietary fat and adipose tissue metabolism in ruminants, pigs, and rodents: A review. J. Dairy Sci. 76:38973931.

DePeters, E. J., J. B. German, S. J. Taylor, S. T. Essex, and H. PerezMonti. 2001. Fatty acid and triglyceride composition of milk fat from lactating Holstein cows in response to supplemental canola oil. J. Dairy Sci. 84:929-936.

Donovan, D. C., D. J. Schingoethe, R. J. Baer, J. Ryali, A. R. Hippen, and S. T. Franklin. 2000. Influence of dietary fish oil on conjugated linoleic acid and other fatty acids in milk fat from lactating dairy cows. J. Dairy Sci. 83:2620-2628.

Douglas, G. N., T. R. Overton, H. G. Bateman II, H. M. Dann, and J. K. Drackley. 2006. Prepartal plane of nutrition, regardless of dietary energy source, affects periparturient metabolism and dry matter intake in Holstein cows. J. Dairy Sci. 89:2141-2157.

Douglas, G. N., T. R. Overton, H. G. Bateman II, and J. K. Drackley. 2004. Peripartal metabolism and production of Holstein cows fed diets supplemented with fat during the dry period. J. Dairy Sci. $87: 4210-4220$.

Drackley, J. K., J. J. Veenhuizen, M. J. Richard, and J. W. Young. 1991. Metabolic changes in blood and liver of dairy cows during either feed restriction or administration of 1,3-butanediol. J. Dairy Sci. 74:4254-4264.

Flatmark, T., A. Nilsson, J. Kvannes, T. S. Eikhom, M. H. Fukami, H. Kryvi, and E. N. Christiansen. 1988. On the mechanism of induction of the enzyme systems for peroxisomal beta-oxidation of fatty acids in the rat liver by diets rich in partially hydrogenated fish oil. Biochim. Biophys. Acta 962:122-130.

Frayn, K. N., S. Shalid, R. Hamlani, S. M. Humphreys, M. L. Clark, B. A. Fielding, O. Boland, and S. W. Coppack. 1994. Regulation of 
fatty acid movement in human adipose tissue in the postabsorptiveto-postprandial transition. Am. J. Physiol. 266:E308-E317.

Giudetti, A. M., A. C. Beynen, A. G. Lemmens, G. V. Gnoni, and M. J. H. Geelen. 2003. Hepatic fatty acid metabolism in rats fed diets with different contencts of C18:0, C18:1-cis, and C18:1-trans isomers. Br. J. Nutr. 90:887-893.

Grummer, R. R., and D. J. Carroll. 1991. Effects of dietary fat on metabolic disorders and reproductive performance of dairy cattle. J. Anim. Sci. 69:3838-3852.

Hoffman, W. S. 1937. A rapid photoelectric method for the determination of glucose in blood and urine. J. Biol. Chem. 120:51-55.

Johnson, M. M., and J. P. Peters. 1993. Technical note: an improved method to quantify nonesterified fatty acids in bovine plasma. J. Anim. Sci. 71:753-756.

Juchem, S. O. 2007. Lipid digestion and metabolism in dairy cows: Effects on production, reproduction, and health. PhD Diss. University of California, Davis.

Jump, D. B. 2002. Dietary polyunsaturated fatty acids and regulation of gene transcription. Curr. Opin. Lipidol. 13:155-164.

Jump, D. B., and S. D. Clarke. 1999. Regulation of gene expression by dietary fat. Annu. Rev. Nutr. 19:63-90.

Jump, D. B., S. D. Clarke, O. MacDougald, and A. Thelen. 1993 Polyunsaturated fatty acids inhibit S14 gene transcription in rat liver and cultured hepatocytes. Proc. Natl. Acad. Sci. USA 90:8454-8458.

Lo, S., J. C. Russell, and A. W. Taylor. 1970. Determination of glycogen in small tissue samples. J. Appl. Physiol. 28:234-236.

Martin, P. G., H. Guillou, F. Lasserre, S. Dejean, A. Lan, J. M. Pascussi, M. Sancritstobal, P. Legrand, P. Besse, and T. Pineau. 2007. Novel aspects of PPARalpha-mediated regulation of lipid and xenobiotic metabolism revealed through a nutrigenomic study. Hepatology 45:767-777.

Mashek, D. G., S. J. Bertics, and R. R. Grummer. 2002. Metabolic fate of long-chain unsaturated fatty acids and their effects on palmitic acid metabolism and gluconeogenesis in bovine hepatocytes. J. Dairy Sci. 85:2283-2289.

Mashek, D. G., S. J. Bertics, and R. R. Grummer. 2005. Effects of intravenous triacylglycerol emulsions on hepatic metabolism and blood metabolites in fasted dairy cows. J. Dairy Sci. 88:100109.

Mashek, D. G., and R. R. Grummer. 2003. Effects of long chain fatty acids on lipid and glucose metabolism in monolayer cultures of bovine hepatocytes. J. Dairy Sci. 86:2390-2396.

Mater, M. K., A. P. Thelen, D. A. Pan, and D. B. Jump. 1999. Sterol response element-binding protein 1c (SREBP1c) is involved in the polyunsaturated fatty acid suppression of hepatic S14 gene transcription. J. Biol. Chem. 274:32725-32732.

Matsuzaka, T., H. Shimano, N. Yahagi, M. Amemiya-Kudo, T. Yoshikawa, A. H. Hasty, Y. Tamura, J. Osuga, H. Okazaki, Y. Iizuka, A. Takahashi, H. Sone, T. Gotoda, S. Ishibashi, and N.
Yamada. 2002. Dual regulation of mouse $\Delta-5$ and $\Delta-6$ desaturase gene expression by SREBP-1 and PPAR $\alpha$. J. Lipid Res. 43:107114 .

Mattos, R., C. R. Staples, A. Arteche, M. C. Wiltbank, F. J. Diaz, T. C. Jenkins, and W. W. Thatcher. 2004. The effects of feeding fish oil on uterine secretion of $\mathrm{PGE}_{2 \alpha}$, milk composition, and metabolic status of periparturient Holstein cows. J. Dairy Sci. 87:921-932.

Monroy, G., F. H. Rola, and M. E. Pullman. 1972. A substrate- and position-specific acylation of sn-glycerol 3-phosphate by rat liver mitochondria. J. Biol. Chem. 247:6884-6894.

Moussavi, A. R., R. O. Gilbert, T. R. Overton, D. E. Bauman, and W. R. Butler. 2007. Effects of feeding fish meal and n-3 fatty acids on milk yield and metabolic responses in early lactating dairy cows. J. Dairy Sci. 90:136-144.

NRC. 2001. Nutrient Requirements of Dairy Cattle. 7th rev. ed. National Academy Press, Washington, DC.

Ren, B., A. P. Thelen, J. M. Peters, F. J. Gonzalez, and D. B. Jump. 1997. Polyunsaturated fatty acid suppression of hepatic fatty acid synthase and S14 gene expression does not require peroxisome proliferators-activated receptor alpha. J. Biol. Chem. 272:2682726832.

Schrock, C. G., and W. E. Conner. 1975. Incorporation of the dietary fatty acid (C18:1) into the serum lipids, the serum lipoproteins and adipose tissue. Am. J. Clin. Nutr. 28:1020-1027.

Uauy, R., P. Mena, and C. Rojas. 2000. Essential fatty acids in early life: Structural and functional role. Proc. Nutr. Soc. 59:3-15.

van Knegsel, A. T., H. van den Brand, J. Dijkstra, S. Tamminga, and B. Kemp. 2005. Effect of dietary energy source on energy balance, production, metabolic disorders and reproduction in lactating dairy cattle. Reprod. Nutr. Dev. 45:665-688.

van Knegsel, A. T., H. van den Brand, J. Dijkstra, W. M. van Straalen, R. Jorritsma, S. Tamminga, and B. Kemp. 2007. Effect of glucogenic vs. lipogenic diets on energy balance, blood metabolites, and reproduction in primiparous and multiparous dairy cows in early lactation. J. Dairy Sci. 90:3397-3409.

Weiss, W. P., H. R. Conrad, and N. R. St-Pierre. 1992. A theoretically based model for predicting total digestible nutrient values of forages and concentrates. Anim. Feed Sci. Technol. 39:95-110.

Whitlock, L. A., D. J. Schingoethe, A. R. Hippen, K. F. Kalscheur, R. J. Baer, N. Ramaswamy, and K. M. Kasperson. 2002. Fish oil and extruded soybeans fed in combination increase conjugated linoleic acids in milk of dairy cows more than when fed separately. J. Dairy Sci. 85:234-243.

Wildman, E. E., G. M. Jones, P. E. Wagner, R. L. Boman, H. R. Troutt, and T. N. Lesch. 1982. A dairy cow body condition scoring system and its relationship to selected production characteristics. J. Dairy Sci. 65:495-501.

Yang, Y. T., J. M. Rohde, and R. L. Baldwin. 1978. Dietary lipid metabolism in lactating dairy cows. J. Dairy Sci. 61:1400-1406. 